\title{
A REFORMA DO ENSINO MÉDIO E AS DESIGUALDADES NO BRASIL
}

\author{
Marcília Elis Barcellos; Elisabeth Gonsalves de Souza; Laura Roberta Fontana; Soraia Wanderosck \\ Toledo; Celso Braga Junior \\ marcilia12@hotmail.com; elisabethsouza.cefetrj@gmail.com; lauraroberta@mast.br; swtoledo@ \\ hotmail.com; celsobj@gmail.com \\ 10.15628/rbept.2017.6127 \\ Artigo submetido em set/2017 e aceito em out/2017
}

\section{RESUMO}

O presente artigo apresenta resultados de análises realizadas por um grupo de estudo composto por professores que atuam na Educação Básica e Superior acerca das mudanças definidas para o Ensino Médio por meio da Lei 13.415/17, bem como, suas possíveis consequências. As análises partiram de leituras de Bourdieu, acrescidas de ideias gramscianas. O levantamento histórico das mudanças propostas para a educação formal brasileira, desde o Manifesto dos Pioneiros (1932) e com ênfase na legislação, se configurou em contexto para as discussões. Como conclusões, a confirmada crise no Ensino Médio foi entendida como resultado de dicotomias que fizeram desentender a identidade desse segmento educacional, como: formação propedêutica ou profissional, ensino público ou privado, classe dominante ou trabalhadores, ricos ou pobres. A reforma proposta em 2016/2017 aprofunda a crise identitária do Ensino Médio ao fragmentar os conhecimentos em itinerários formativos opcionais, o que, financeiramente impraticável, acabará por promover diferentes formações que serão, inevitavelmente, referenciadas à situação socioeconômica dos alunos e às condições das instituições de ensino. Assim, apesar das insistentes propagandas que informam liberdade de escolha para os diferentes alunos, a atual reforma do Ensino Médio representa um retrocesso nas políticas educacionais ao legitimar as desigualdades socioeconômicas e reproduzir injustiça social na qual está agonizando opaís.

Palavras-Chaves: Ehsino Médio, Reforma, Desigualdades, Bourdieu, Gramsci. 


\section{ABSTRACT}

This paper presents the results of analyzes about changes defined for High School through Law 13.415 / 17 and its possible consequences carried out by a group of teachers who work in Basic and Higher Education. The analyzes came from the Bourdieu's reading and Gramsci's ideas. The historical review of the changes proposed for Brazilian formal education, since the Pioneers Manifesto (1932) and with an emphasis on legislation, has been configured in the context of the discussions. As conclusions, the confirmed crisis in the High School Education was understood as result of dichotomies such as: propaedeutic or professional education; public or private schools; the ruling class or workers; the rich or poor. The reform carried out by the Law deepens the identity crisis of high school by fragmenting knowledge into optional training itineraries. Once it is financially impracticable, this new model will promote different ways of education that will inevitably be referenced to the socioeconomic situation of the students and the conditions of the educational institutions. Thus, in spite of the insistent advertisements of the federal government that inform autonomy of choice for the different students, the current reform of High School represents a setback in educational policies by legitimizing socioeconomic inequalities and reproducing social injustice which the country is agonizing.

KEYWORDS: High School, Reform, Inequalities, Bourdieu, Gramsci. 


\section{APRESENTAÇÃO}

As discussões sobre a qualidade do Ensino Médio no Brasil não são recentes. 0 documento que resultou no Manifesto dos Pioneiros da Educação Nova, de 1932 já apontava o ensino secundário (que hoje compreende os anos finais do Ensino Fundamental e o Ensino Médio) como ponto nevrálgico da educação brasileira. Desde então muito se vem discutindo sobre políticas educacionais que sejam capazes de reorganizar o ensino, em especial, o ensino médio, mas pouco temos conseguido de fato, realizar. Este é um pensamento comum a todos aqueles envolvidos com os processos educacionais brasileiros. Porém, o fato de que se necessite realizar uma reforma educacional neste nível de ensino, não permite que esta reforma seja feita de forma unilateral e imposta por um governo do qual se questiona a legitimidade e o projeto de nação a que se propõe.

O caminho que aqui percorremos vai desde os manifesto dos pioneiros da educação nova de 1932 passando por várias reformas em momentos de mais e menos democracia da história brasileira. Nossa ênfase recai na questão da formação profissional que estabelece diferentes relações com o ensino secundário ao longo desse período em função de diferentes projetos de sociedade e da consequente divisão social do trabalho preconizada por esses projetos.

Buscaremos neste texto, compreender as mudanças atuais que afetam o ensino médio, estabelecidas de cima para baixo sem discussão com os sujeitos interessados no processo (professores, alunos, agências de educação) e analisar como esta reforma amplia o caráter excludente dos processos educacionais voltando a moldes muito parecidos de um projeto fracassado nos anos 1970. Para tanto nos baseamos no pensamento de Bourdieu a partir dos conceitos de habitus, capital cultural e de causalidade do provável. A forma como a reforma foi proposta e implementada e o desenrolar dos discursos e práticas do governo pós publicitação da reforma nos levaram também a incorporar à análise algumas perspectivas do pensamento gramisciniano a fim de melhor compreender, de forma crítica, essa controversa realidade.

\section{BREVE HISTÓRICO DO ENSINO MÉDIO}

No intuito de compreendermos as mudanças atuais que afetam o ensino médio, é necessário voltar no tempo e analisarmos como esse nível de ensino se configurou historicamente, pois não é possível considerarmos as atuais mudanças em curso se não levarmos em conta as dimensões históricas, políticas, econômicas e o conceito de educação que norteia estas alterações.

Sabemos que o ensino brasileiro nasceu de uma junção público/privada com a finalidade muito específica de educar os filhos das elites em detrimento da maioria da população e assim se manteve até os anos 1930, ou seja, a marca fundamental do ensino brasileiro do descobrimento até o século XX é de selecionar, não de incluir. Esta mesma lógica permanece pós 1930, mas disfarçada numa outra funcionalidade: ao invés de dificultar o acesso da população aos processos de escolarização, em especial, de escolarização pública, a educação profissional que se consolida no Brasil pós 1940 tem característica mais seletiva, de indicar aqueles que comporiam as classes dirigentes do país e aqueles que seriam destinados à classe trabalhadora. A dualidade dos sistemas de ensino (público e privado) e a dualidade das propostas educacionais (formação científica e formação técnica) separava claramente a população em governantes e governados. Sendo os primeiros aqueles com melhores condições socioeconômicas e por conseguinte mais capital cultural: 
O capital cultural é um ter que se tornou ser, uma propriedade que se faz corpo e tornou-se parte integrante da "pessoa", um habitus. Aquele que o possui "pagou com sua própria pessoa" e com aquilo que tem de mais pessoal, seu tempo. (BOURDIEU 2013 ,p. 74)

Vale ressaltar que essa dualidade, característica do sistema educacional brasileiro, emerge com mais força de tempos em tempos e, não coincidentemente em períodos de pouca (ou nenhuma) participação democrática. Foi assim durante todo o período colonial, imperial e mesmo na primeira república.

A consolidação da democracia, sonhada no período getulista, no início dos anos 1930, não obteve êxito, sendo sufocada pelo Estado Novo em 1937. A implantação do Estado Novo rompe com o ideário escolanovista que defendia uma educação pública, laica, gratuita e única e retoma o princípio da dualidade educacional, marca histórica da educação brasileira, de uma educação destinada às elites e uma educação destinadas aos "menos favorecidos". É possível ver no artigo 129 do texto constitucional de 1937 esta dualidade.

(...) 0 ensino prevocacional profissional destinado às classes menos favorecidas é, em matéria de educação, o primeiro dever do Estado. Cumpre-Ihe dar execução a esse dever, fundando institutos de ensino profissional e subsidiando os de iniciativa dos Estados, dos Municípios e dos indivíduos ou associações particulares e profissionaes (BRASIL, art. 129, 1937)

Esta mesma constituição altera ainda o princípio da gratuidade do ensino primário ao estabelecer a cooperação dos "mais favorecidos" aos "menos favorecidos", transformando um direito em uma concessão, ou até mesmo "esmola".

O ensino primario é obrigatorio e gratuito. A gratuidade, porém, não exclui o dever de solidariedade dos menos para com os mais necessitados; assim, por occasião da matricula, será exigida aos que não allegarem, ou notoriamente não puderem allegar escassez de recursos, uma contribuição modica e mensal para a caixa escolar. (BRASIL, art. 130, 1937)

A ideia de uma educação profissional para os menos favorecidos e de uma educação científica para os mais favorecidos vai orientar a construção de leis que regularam esta modalidade de ensino nos anos 1940. Para Alves,

A educação profissionalizante, no Brasil, possui historicamente, características de dualidade e de assistencialismo, que se explicam pela herança do processo de formação social do país, no qual o colonialismo escravocrata influenciou as relações sociais e, no caso, distorceu preconceituosamente a visão sobre trabalho manual e trabalho intelectual perante a sociedade. Esta visão dual ficou presente em toda legislação educacional, que como espelho, reflete as relações sociais do país, e diferencia até os nossos dias a educação profissional e a educação acadêmica. (ALVES, 2010, pág. 5) 
Todos estes fatos elencados podem nos dar uma breve visão de como se estruturou a educação para as massas no Brasil. É por este motivo que é necessário promover lutas em prol de uma educação com base na justiça social, que atenda a todos e que garanta aos brasileiros uma educação de qualidade e não uma educação dual. Como já discutido, são nesses momentos históricos que a dualidade e a separação de classes pelos textos legais se alternam e alteram profundamente as relações estabelecidas, sobretudo o direito dos cidadãos.

Com o fim do Estado Novo, o Brasil se abre para um rápido período democrático, porém de profundas transformações e principalmente, de uma busca pela identidade nacional. Neste contexto surge Paulo Freire com a proposta de uma educação conscientizadora e crítica, que evidencie as necessidades e características do povo brasileiro. Seu projeto educacional emancipador, que tem como base a alfabetização crítica das massas, é rapidamente sepultado pelo regime militar de 1964 . Fica evidente, com o rompimento estabelecido pela ditadura, que os processos educacionais brasileiros demorariam a se reestabelecer, pois nos encontrávamos num momento propício, como pode ser visto nas próprias palavras de Freire:

Nunca, no Brasil, teremos vivido condições mais propícias para uma revisão de nossa educação, em termos de autenticidade, como as de hoje, apesar de todas as contradições que vêm caracterizando a nossa atualidade. Uma das tarefas, aliás, de educação de que precisamos, será mesmo diminuir e até superar algumas das antinomias desta atualidade (FREIRE, 2012, pág. 57).

Assim, mergulhamos num período marcado pelo controle e pela retomada da dicotomia do ensino. A Lei 5692/71, que alterava parte da lei de diretrizes e bases de 1961 (Lei 4024/61), impôs um ensino de segundo grau profissionalizante, atrelando a escola ao mercado detrabalho, propondo uma educação profissional para acatar a exigência americana de formação de mão de obra destinada aos quadros das multinacionais estabelecidas no período do "milagre econômico". Com o segundo grau profissionalizante, o acesso aos cursos superiores, em especial os públicos, só era possível mediante ingresso em cursos pré-vestibulares. Assim, podemos verificar que um dos objetivos da lei em questão era de conter a alta demanda para ensino superior público. Para Xavier,

A reforma de $1^{\circ}$ e $2^{\circ}$ graus (Lei 5692/71) possuía, portanto, uma dupla função: utilitarista e discriminadora. Utilitarista porque tinha em vista a inserção imediata do estudante no mercado de trabalho, e discriminadora porque a "igualdade de oportunidades", via escola, não garantia a ascensão social (XAVIER, 2003, pág. 251)

Neste contexto, os alunos vindos das classes mais pobres da população, quando conseguiam finalizar o segundo grau, restava-Ihes apenas exercer a profissão para a qual, na grande maioria das vezes, não estavam preparados, dada a baixa qualidade dos cursos. Assim, o ensino de segundo grau assumia seu caráter terminalizante.

O que se constatou pós promulgação da Lei 5692/71 foi um desmonte da educação pública. A exigência da profissionalização acompanhada de um baixo investimento nas redes escolares resultou no sucateamento dos estabelecimentos de ensino público. Estes não conseguiram consolidar a proposta da lei e ofereciam uma educação de baixa qualidade, não conseguindo habilitar de forma satisfatória o seu quadro de alunos. De acordo com Xavier, 
As escolas particulares tiveram mais êxito na medida que possuíam recursos para cumprir esse dispositivo da lei (obrigatoriedade da formação profissional). Quanto às escolas públicas, devido à omissão por parte do Estado em repassar recursos, não tiveram condições de realizar o projeto de profissionalização (XAVIER, 2003, pág. 249)

Além de possuírem recursos para a implementação do projeto profissionalizante, as escolas particulares ainda utilizavam de outras estratégias para se tornarem mais atrativas em relação às escolas públicas que eram sucateadas gradativamente. GHIRARDELLI JR.(1990) em seu livro História da Educação aponta que "É claro que as escolas particulares "driblaram" essa lei e continuaram a preparar seus alunos para o ingresso na universidade, porém as escolas públicas eram obrigadas a cumpri-la e a descaracterização de seus cursos foi inevitável”. Assim, além de investirem na formação profissional, tendo em vista a maior facilidade de recursos, as escolas particulares ainda preparavam os alunos para os vestibulares, o que significava um grande diferencial em relação à rede pública. Significava também, e reside neste fato a pior parte, que estava em curso um projeto de privatização do ensino, iniciado com o sucateamento das escolas públicas e consolidado pelas vantagens oferecidas pelas escolas particulares. Neste contexto a dualização se consagra: paga pelo ensino aqueles com condições econômicas para tal. Cabia à parte da população carente de recursos financeiros deixar os bancos escolares e engrossar a massa trabalhadora sem maior qualificação.

Ao final de uma década da edição da lei, o que se notou é que o projeto de profissionalização havia fracassado. As diversas dificuldades de implantação do mesmo levaram o governo a editar, em 1982, a Lei 7044 que encerrava a obrigatoriedade do ensino profissional. Em seu artigo $4^{\circ}$ a referida lei estabelecia que:

$\S 1^{\circ}$ - A preparação para o trabalho, como elemento de formação integral do aluno, será obrigatória no ensino de $1^{\circ}$ e $2^{\circ}$ graus e constará dos planos curriculares dos estabelecimentos de ensino.

$\S 2^{\circ}$ - A preparação para o trabalho, no ensino de $2^{\circ}$ grau, poderá ensejar habilitação profissional, a critério do estabelecimento de ensino. (BRASIL, 1982. p.1)

A promulgação da Lei 7044/82 significou, por parte do governo, o reconhecimento do fracasso da política educacional de profissionalização do ensino para atender às demandas do mercado de trabalho. Porém, a promulgação desta lei não impediu que os reflexos de sua insensatez repercutissem por toda década de 1980. O que se pode ver da educação brasileira nos anos 1980 foi um desmonte total, uma desorganização que é resultado da falta de um projeto educacional voltado para os anseios e necessidades da população.

Esse quadro de precariedade e de dualidade do ensino nacional só começa a se transformar nos anos 1990, bem depois da redemocratização. As discussões dos anos iniciais de 1990 que culminaram na lei de diretrizes e bases da educação nacional 9394/96 apresentam uma nova forma de sepensar o ensino, com limitações, éverdade, mas com uma nova possibilidade detransformação.

A lei 9493/96 estabelece a progressiva extensão da obrigatoriedade e gratuidade ao ensino médio (EM), que corresponde ao antigo $2^{\circ}$ grau. Nesse sentido a chamada educação básica, desejável a todos os cidadãos brasileiros, passa a se completar mediante a conclusão do ensino médio. Essa mesma lei define ainda a autonomia das instituições de ensino para que elaborem seu projeto pedagógico seguindo preceitos democráticos: 
Os sistemas de ensino definirão as normas de gestão democrática do ensino público na educação básica, de acordo com as suas peculiaridades e conforme os seguintes princípios:

I - participação dos profissionais da educação na elaboração do projeto pedagógico da escola;

II - participação das comunidades escolar e local em conselhos escolares ou equivalentes. (BRASIL, 1996)

No que concerne à questão da finalidade a lei 9394/96 define que a educação básica pretende desenvolver o educando, assegurar-lhe a formação comum indispensável para o exercício da cidadania e fornecer-Ihe meios para progredir no trabalho e em estudos posteriores.

0 artigo 26 dispõe sobre os currículos do ensino fundamental e médio. Ficam estabelecidos como obrigatórios o estudo da língua portuguesa e da matemática, 0 conhecimento do mundo físico e natural e da realidade social e política, especialmente do Brasil, assim como o ensino da arte e a educação física. Em relação a história do Brasil ainda estabelece que a mesma deve levar em conta as contribuições das diferentes culturas e etnias para a formação do povo brasileiro, especialmente das matrizes indígena, africana e europeia.

Dentre as diretrizes fornecidas pelo documento está a difusão de valores fundamentais ao interesse social, aos direitos e deveres dos cidadãos, de respeito ao bem comum e à ordem democrática e a orientação para o trabalho.

Especificamente sobre o ensino médio a lei dispõe que suas finalidades são:

I - a consolidação e o aprofundamento dos conhecimentos adquiridos no ensino fundamental, possibilitando o prosseguimento de estudos;

II - a preparação básica para o trabalho e a cidadania do educando, para continuar aprendendo, de modo a ser capaz de se adaptar com flexibilidade a novas condições de ocupação ou aperfeiçoamento posteriores;

III - o aprimoramento do educando como pessoa humana, incluindo a formação ética e o desenvolvimento da autonomia intelectual e do pensamento crítico;

IV - a compreensão dos fundamentos científico-tecnológicos dos processos produtivos, relacionando a teoria com a prática, no ensino de cada disciplina.

(BRASIL, 1996)

Diante desse exposto fica claro que a vocação do ensino médio (EM) definida pela LDB 9394/96 não é eminentemente propedêutica, ou seja, preparatória para o ingresso no Ensino Superior. Uma das funções desse nível continua sendo a preparação para o prosseguimento nos estudos, nas palavras da lei, mas como etapa da educação básica é desejável que adquira também outros contornos, visto que nem toda a população brasileira estará fadada a cursar o ensino superior. 
Nesse sentido o texto da lei expressa também uma preocupação com a formação para o exercício da cidadania e para o mundo do trabalho. Em relação à formação técnica, ou seja, na qual o nível médio habilita aos exercícios de profissões técnicas a lei dispõe no artigo 36 que:

$\S 1^{\circ} \mathrm{O}$ ensino médio, atendida a formação geral do educando, poderá prepará-lo para o exercício de profissões técnicas.

$\S 3^{\circ}$ Os cursos do ensino médio terão equivalência legal e habilitarão ao prosseguimento dos estudos.

$\S 4^{\circ}$ A preparação geral para o trabalho e, facultativamente, a habilitação profissional, poderão ser desenvolvidas nos próprios estabelecimentos de ensino médio ou em cooperação com instituições especializadas em educação profissional.

(BRASIL, 1996)

É justamente nesse entendimento que reside uma importante ruptura como modelo anterior de $2^{\circ}$ grau. $O$ ensino médio aqui definido não é adequado apenas ao prosseguimento nos estudos ou à formação profissional. Isso porque como assegura o texto da lei a preparação para as profissões técnicas pode ocorrer, mas desde que seja atendida também a formação geral do educando a partir da realização do ensino médio nos mesmos moldes definidos para todos os alunos. Ou seja, o ensino médio é o mesmo para todos e a formação técnica pode ser oferecida de modo complementar. 0 artigo 40 define que:

Art. 40. A educação profissional será desenvolvida em articulação com o ensino regular ou por diferentes estratégias de educação continuada, em instituições especializadas ou no ambiente de trabalho.

(BRASIL, 1996)

Nesse momento assistimos a uma ruptura, ao menos no que se refere à legislação em si, com o modelo dualista tão presente na história educacional brasileira. A formação do ensino básico desejável a todos os jovens brasileiros é a conclusão do ensino médio regular, como preparação para o prosseguimento nos estudos e também a formação para o exercício da cidadania. Atendida essa formação pode ser articulada complementarmente alguma educação profissional.

De acordo com o Documento Base da Educação Profissional Técnica de Nível Médio Integrada ao Ensino Médio (2007), apesar de nesse período já acontecer a defesa de uma formação profissional lato sensu, que aponta para a formação baseada na politecnia, ou seja, em múltiplos aspectos humanísticos e científicos, a LDB 9694/96 acaba por ser efetivada com um texto "minimalista" que caracteriza a Educação Profissional com um "apêndice", já que indica que a educação escolar brasileira é composta pela Educação Básica (Ensinos Infantil, Fundamental e Médio) e Superior. O Ensino Profissional, então, aparece à margem na composição da estrutura educacional.

Art. 21. A educação escolar compõe se de:

I a educação básica, formada pela educação infantil, ensino fundamental e ensino médio;

Il educação superior.

(BRASIL 1996) 
O decreto 2208/1997 regulamenta a parte da LDB referente ao ensino profissional. Essa modalidade passa a ter três níveis de ensino dentre as quais o técnico, que é, segundo o texto da lei, destinado a proporcionar habilitação profissional a alunos matriculados ou egressos do ensino médio, para o exercício de funções demandadas pelo mundo do trabalho. Fica regulamentado ainda que a educação profissional de nível técnico terá organização curricular própria e independente do ensino médio, podendo ser oferecida de forma concomitante ou sequencial a este.

Uma análise a partir desse decreto, informa que o Ensino Profissional tem um caráter eminentemente instrumental, cabendo ao Ensino Médio "o aprimoramento do educando como pessoa humana, incluindo a formação ética e o desenvolvimento da autonomia intelectual e do pensamento crítico" (BRASIL, 1996).

Art $1^{\circ}$ A educação profissional tem por objetivos:

I - promover a transição entre a escola e o mundo do trabalho, capacitando jovens e adultos com conhecimentos e habilidades gerais e específicas para o exercício de atividades produtivas;

Il - proporcionar a formação de profissionais, aptos a exercerem atividades específicas no trabalho, com escolaridade correspondente aos níveis médio, superior e de pós-graduação;

III - especializar, aperfeiçoar e atualizar o trabalhador em seus conhecimento tecnológicos;

IV - qualificar, reprofissionalizar e atualizar jovens e adultos trabalhadores, com qualquer nível de escolaridade, visando a sua inserção e melhor desempenho no exercício do trabalho.

(BRASIL 1997)

Concomitante a esse decreto, aconteceu o Programa de Expansão do Ensino Profissional (PROEP) que promoveu privatizações do Ensino Profissional, além da reestruturação da Rede Federal de Educação Profissional. Essa reestruturação teve como bases a competitividade no mercado educacional, a busca por arrecadação a partir da prestação de serviços à comunidade, por aumento da capacidade de autofinanciamento capaz de diminuir a participação do orçamento público nesse segmento.

As mudanças promovidas pela Lei 9394/96 não foram capazes de superar de fato a dicotomia entre os conhecimentos gerais atribuídos ao Ensino Médio, baseados nos conteúdos das letras, das ciências e das humanidades, historicamente oferecidos às classes dirigentes, e os conhecimentos específicos relacionados à formação instrumental para o trabalho, oferecidos pelo Ensino Profissional em nível Médio, direcionados às classes trabalhadoras.

Em 2004 a educação profissional sofre uma nova mudança. O decreto 2208/1997 é revogado na mesma ocasião em que é promulgado o decreto 5154/2004. Dentre as mudanças introduzidas por este decreto destacamos a supressão dos itens de postulavam a independência entre o ensino médio e o ensino técnico profissionalizante. Isso abre caminho para a definição de uma nova modalidade de ensino: o ensino médio integrado.

O parecer 39/2004 do Conselho Nacional de Educação explora detalhadamente o decreto 5154/2004 deixando bem claro que a modalidade integrada requer um projeto pedagógico próprio na qual as áreas de conhecimento gerais devem ser integradas aos 
saberes da área técnica. É ressaltado ainda que o Ensino Médio na modalidade integrada prevê um acréscimo de carga horária de acordo com a necessidade de cada formação profissional de modo que a formação técnica não substitua a formação geral. Ao contrário espera-se que elas se articulem e se complementem.

Frigotto (2016) aponta alguns termos das contradições que resultaram no decreto $5154 / 2004$. Segundo esse autor o decreto expressa a luta que foi travada politicamente em torno da questão da educação profissional, por um lado pelos representantes do setor produtivo como a FIRJAN, e por outro pelos especialistas da área da educação alinhados como o governo do então presidente Lula defensores da educação politécnica nos moldes gramscianos.

O resultado dessa disputa foi a inclusão da formação técnica integrada de nível médio como possibilidade formativa por um lado, e por outro lado a manutenção de outras formas de articulação, como a formação concomitante permitindo ao sistema S, por exemplo, manter seus cursos técnicos de forma independente.

Os representantes do setor produtivo ganharam força nessa disputa dentro da proposta. Segundo o Documento Base da Educação Profissional Técnica de Nível Médio Integrada ao Ensino Médio (2007), uma educação baseada na politecnia, na formação omnilateral dos sujeitos, pressupõe terminalidade tardia. Infelizmente, a urgência pela remuneração imposta pelas condições econômicas da maioria da população brasileira, leva à necessidade de uma preparação que possibilite aos jovens inserção mais imediata no mercado de trabalho, ainda que isso signifique uma preparação mais instrumental, que, ao final das contas, será responsável pela reprodução de formas de exploração econômica e social que remetem a uma sociedade desequilibrada e injusta.

Dessa forma, no bojo da proposta, é vislumbrada a impossibilidade imediata de implantação da mesma. A integração Médio-Profissional se caracteriza, então, como uma etapa que visa uma futura e possível formação educacional básica omnilateral, na qual o trabalho é entendido como realização humana, além de uma prática econômica, a ciência como o conhecimento produzido pela humanidade e a cultura como valores éticos e estéticos que orientam a sociedade. Trabalho, ciência e cultura, nesse sentido, deverão ser conhecimentos oferecidos a todos os sujeitos sociais, sem distinção.

Bourdieu (2013) informa que a esperança de vida atrelada às condições regidas pelas hierarquias sociais, acaba por promover uma seleção que, aparentemente livre e equânime, consolida, legitima e perpetua as desigualdades reais. Assim, para que as escolhas não sejam baseadas em condições de vida, o capital cultural precisa ser trabalhado de forma ominilateral em relação a todos, ricos e pobres, no sentido de que sejam oferecidos subsídios para escolhas verdadeiramente livres.

\section{A CRISE DO ENSINO MÉDIO}

Para compreender o cenário de crise do EM, que culminou, a partir de uma conjuntura política ímpar e complexa, numa reforma na Lei de Diretrizes e Bases da Educação brasileira, feita às pressas, por meio de medida provisória, é necessário ir além do âmbito dos documentos oficiais.

É sabido que o discurso oficial, nesse caso governamental, sobre um currículo escolar em diferentes níveis, é apenas um dentre vários âmbitos existentes na construção das práticas educacionais concretas (LOPES, 2011). 
O caso do atual EM ilustra bem essa questão. Apesar do teor indicado pelo discurso oficial da Lei 9394/96, o EM ainda hoje tem uma função predominantemente propedêutica, ou seja, de preparação para o Ensino Superior. Isso se torna um problema quando se assume esse nível como etapa conclusiva da educação básica, ou seja, desejável a todos os brasileiros, num país onde apenas 18,1 \% dos jovens de 18 a 24 anos têm acesso ao nível superior de ensino .

Pela lei, temos um ensino médio que deve preparar o aluno para o prosseguimento nos estudos, mas também é um nível obrigatório a toda uma classe de jovens que não tem aspirações nem acesso ao ensino superior. Isso em última análise relega ao próprio ensino médio regular o desafio de justificar-se em si mesmo, para além da vocação propedêutica. Por outro lado, a 9394/96 e os documentos subsequentes como diretrizes e parâmetros curriculares nunca chegaram a causar de fato mudanças significativas nas práticas curriculares adotadas pelo EM.

A base nacional comum curricular (BNCC) prevista na Lei 9394/96 estava em vias de ser publicada em sua versão final apenas em meados de 2016, mas o impeachment da presidente Dilma estagnou o processo. Até o momento da redação deste artigo não temos uma BNCC publicada para o ensino médio.

As escolas de EM continuaram basicamente usando os mesmos currículos do antigo segundo grau pautados nos conteúdos exigidos nos exames de ingresso para as universidades. A organização das disciplinas, seu isolamento, os currículos enciclopédicos (muitas vezes simplificações dos manuais de Ensino Superior), característicos do então $2^{\circ}$ grau, ficaram e ainda estão muito arraigados nas práticas docentes (e também na formação de professores).

A formação para a cidadania preconizada pela LDB e por outros documentos como os Parâmetros Curriculares Nacionais (PCN) não chegaram a sair do papel na esmagadora maioria das escolas públicas brasileiras. Em parte pelas dificuldades inerentes a uma reforma curricular que é colocada de cima para baixo (GOODSON, 2010), em parte pela dificuldade de modificar práticas muitos naturalizadas (CHERVEL, 1992), o ensino médio continuou mantendo sua vocação apenas de formação para o ensino superior.

Segundo Ramos (2005) as mudanças pós 9394/96 cultivavam a ideia de que o modelo produtivo exigia a adaptação dos sujeitos ao trabalho flexível, e portanto, do ponto de vista pedagógico seriam mudanças que daria ênfase às dimensões cognitivas e comportamentalistas da educação, negligenciando as dimensões epistemológicas e sóciopolíticas, e recaindo sobre o experimentalismo. Mas a autora ressalta ainda que nem essa perspectiva foi apreendida pelos educadores dadas as limitações da política oficial.

O número de alunos matriculados no EM cresceu de forma significativa nos anos 1990 . Grande parte da população brasileira, antes sem acesso ao EM, passa a ter vagas disponíveis para se matricular nesse nível de ensino. E a partir daí que a crise se acirra. 0 EM apresenta de fato os piores números no Índice de Desenvolvimento da Educação Básica IDEB e números de evasão preocupantes . O IDEB do EM estava em 3,5 pontos no ano de 2016, numa escala de 10 com média projetada de 4,0 pontos para o mesmo período. Este índice, apesar de todas as discussões que podem emergir a partir dele, indica que é urgente e necessário se pensar numa reforma.

Não é difícil constatar que a manutenção de um currículo pensado para jovens de elite aspirantes ao ES é altamente desestimulante para atender aos jovens dos setores populares. 
Bourdieu (2013) desvela bem o mecanismo pelo qual a escola, a partir da definição de seus currículos e práticas acaba por selecionar os estudantes que estão de acordo com uma determinada cultura e excluir aqueles que não se adaptam a ela:

Com efeito, para que sejam favorecidos os mais favorecidos e desfavorecidos os mais desfavorecidos é necessário e suficiente que a escola ignore, no âmbito dos conteúdos do ensino que transmite, dos métodos e técnicas de transmissão e dos critérios de avaliação, as desigualdades culturais entre as crianças das diferentes classes sociais. (BOURDIEU, 2013, p. 53)

A escola de nível médio vem a partir dos anos 1990 cada vez mais recebendo jovens das classes historicamente menos favorecidas. E ao agir com esses jovens de modo idêntico ao que era antes praticado com alunos mais favorecidos, esses últimos aspirantes naturais ao ES, cria-se a crise a qual nos remetemos neste artigo.

Os jovens de mais alto capital cultural com seu ethos de classe alta (BOURDIEU, 2013) tem uma clara motivação para cursar o ensino médio: o acesso ao ensino superior. Além disso a cultura legitimada pela escola se alinha com a cultura do grupo ao qual pertencem. Desde o modo de falar até o acesso a bens culturais diversos.

Já para os jovens oriundos de classes menos favorecidas o ethos tem relação clara com o fracasso escolar. O EM faz pouco ou nenhum sentido para o jovem que não tem uma real aspiração ao ES. Assim o modelo propedêutico por si só exclui uma parcela enorme dos jovens brasileiros de 14 a 18 anos.

É preciso ainda considerar que na aspiração de preparar o jovem para a universidade o EM se aproxima de sua linguagem. E a universidade é, por excelência, segundo Bourdieu (2013), o lugar da cultura aristocrática. Se aproximando da cultura da elite o EM se distancia dos jovens de classes menos favorecidas:

A cultura da elite é tão próxima da cultura escolar que as crianças originárias de um meio pequeno burguês (ou a fortiori), camponês e operário) não podem adquirir, senão penosamente, o que é herdado pelos filhos das classes cultivadas. (BOURDIEU, 2013, p. 29)

\section{A REFORMA COMO MANUTENÇÃO E APROFUNDAMENTO DAS DESIGUALDADES}

Analisaremos aqui as principais alterações realizadas pela Lei $n^{\circ} 13.415$ de 16 de fevereiro de 2017, cuja origem remonta à Medida Provisória n 746 de 2016, e suas possíveis consequências no atual contexto educacional brasileiro. Além de realizar alterações na LDB e no FUNDEB, a referida Lei ainda revoga a Lei $n^{\circ} 11.161$ de 2005, que dispõe sobre o ensino de língua espanhola, e institui a Política de Fomento à Implementação de Escolas de Ensino Médio em Tempo Integral. Nosso enfoque principal reside em analisar as alterações produzidas na Lei 9394/96 e suas possíveis consequências no atual contexto em que o campo educacional já se encontra bastante precarizado e de hegemonia de políticas de austeridade que incluem cortes em gastos públicos e limitações orçamentárias por parte do governo, cujo principal instrumento é a Emenda Constitucional 95/2016, que limita os gastos públicos por 20 anos. 
Uma das alterações mais importantes produzidas pela Lei $n^{\circ} 13.415$ relaciona-se ao aumento da carga horária mínima anual, que passará das atuais 800 horas para o ensino fundamental e médio (distribuídas por ao menos 200 dias de efetivo trabalho escolar), para 1.400 horas. A partir de março de 2017, os sistemas de ensino deverão oferecer "no prazo máximo de cinco anos, pelo menos mil horas anuais de carga horária". 0 aumento da carga horária tem por finalidade a implementação gradativa do ensino médio em tempo integral nas escolas das redes pública e privada.

Um inevitável questionamento diz respeito ao montante de investimentos necessários à implementação do ensino médio integral em escolas das redes pública e privada, já que o aumento do tempo de permanência dos alunos na escola demandará incrementos não apenas em infraestrutura (mais ou maiores salas de aula, bibliotecas, laboratórios, etc.) como também nos quadros de professores e outros profissionais da educação e demais funcionários necessários ao funcionamento do cotidiano escolar. Daí o estabelecimento da Política de Fomento à Implementação de Escolas de Ensino Médio em Tempo Integral pela mesma lei, que:

prevê o repasse de recursos do Ministério da Educação para os Estados e para o Distrito Federal pelo prazo de dez anos por escola, contado da data de início da implementação do ensino médio integral na respectiva escola, de acordo com termo de compromisso a ser formalizado entre as partes (...).

A lei ainda diz que "§ 20 A transferência de recursos será realizada anualmente, a partir de valor único por aluno, respeitada a disponibilidade orçamentária para atendimento, a ser definida por ato do Ministro de Estado da Educação" (grifos nossos). De acordo com o portal do MEC, "Está previsto um investimento do Governo Federal de R\$̦ 1,5 bilhão até 2018, correspondendo a R\$ 2.000 por aluno/ano e criando 500 mil novas matrículas de tempo integral". No atual contexto das políticas de austeridade já mencionadas, é importante notar a existência no texto legal de dispositivo que condiciona a transferência de recursos à disponibilidade orçamentária e sua definição por ato do Ministro da Educação.

No que concerne às associações de escolas particulares, representantes destas argumentaram recentemente que o aumento da carga levará ao inevitável aumento das mensalidades, e que apenas uma minoria será capaz de pagar pelo ensino em tempo integral.

Outra alteração importante é a que se refere à flexibilização da grade curricular: no lugar dos conteúdos das 13 disciplinas tradicionais, a reforma torna obrigatórias nos três anos do ensino médio apenas as disciplinas de português e matemática (a língua inglesa aparece como a língua estrangeira obrigatória para o ensino médio, mas não há menções no texto sobre a obrigatoriedade de outras disciplinas). Um mínimo de $60 \%$ (um máximo de 1800 horas) da carga horária deverá constar de conteúdos obrigatórios comuns estipulados pela Base Nacional Curricular Comum (BNCC), ainda a ser definida. Os $40 \%$ restantes oferecerão conteúdos organizados em quatro itinerários formativos, e as escolas deverão ofertar ao menos um desses itinerários. Caberá ao aluno optar por um desses itinerários ou pela formação técnica e profissional. 
Art. 36. O currículo do ensino médio será composto pela Base Nacional Comum Curricular e por itinerários formativos, que deverão ser organizados por meio da oferta de diferentes arranjos curriculares, conforme a relevância para o contexto local e a possibilidade dos sistemas de ensino, a saber:

I - linguagens e suas tecnologias;

II - matemática e suas tecnologias;

III - ciências da natureza e suas tecnologias;

IV - ciências humanas e sociais aplicadas;

$\checkmark$-formação técnica e profissional."

Um dos grandes motes da propaganda governamental para conseguir a adesão da população à reforma é a maior liberdade de escolha que esta proporcionará aos estudantes, que poderão optar pelo itinerário formativo de seu interesse para o aprofundamento de seus estudos. Porém, essa propagada liberdade de escolha pode, em verdade, ser uma quimera: uma vez que não há a obrigatoriedade dos estabelecimentos de ensino oferecerem todos os itinerários formativos e que uma grande parte das escolas enfrentam problemas estruturais e de falta de profissionais, o que poderá acontecer de fato é justamente a limitação da escolha do aluno aos itinerários oferecidos pelos estabelecimentos. Ou seja, o aluno escolherá o itinerário que a escola terá capacidade de oferecer de acordo com suas limitações de infra estruturais e de pessoal: se a escola só for capaz de oferecer um único itinerário, será esse que o aluno irá, sem alternativas, seguir. Como resultado, nem todos terão acesso a todos os conteúdos, aumentando a já imensa desigualdade de nosso sistema educacional. Nos parece que com a reforma está sendo recriado o mecanismo de dupla formação e o espaço para a formação profissional que visa meramente instrumentar o trabalhador.

Dentro dessa lógica, os sistemas de ensino ainda poderão usar a especialização em uma das áreas de formação por parte dos estabelecimentos de ensino como uma forma de contornar a necessidade de contratação de profissionais de disciplinas específicas: se não há professores de química, matemática e física, por exemplo, em um estabelecimento, a solução poderá ser oferecer itinerários formativos apenas na área de linguagens e suas tecnologias. Ou seja, existe a possibilidade de a reforma produzir uma imensa variabilidade na forma como as escolas passarão a ofertar o ensino médio, com algumas poucas escolas sendo capazes de oferecer todos os itinerários, outras apenas alguns, ou ainda estabelecimentos que ofertarão somente um.

A opção de escolha do aluno pode ser encarada como um mecanismo que oferta possibilidades que de fato não existem. Em primeiro lugar porque o aluno mais desfavorecido, da escola mais desfavorecida, terá que optar entre uma ou duas modalidades que sua escola lhe ofertar. Possivelmente uma delas o ensino técnico.

É possível assimilar ainda o conceito de causalidade do provável definido por Bourdieu (2015), segundo o qual as chances que são apropriadas pelos alunos estão imbricadas em seu habitus, que é uma matriz de respostas previamente adaptadas segundo uma estrutura de distribuição das diferentes espécies de capital cultural, o que levaria a uma prática objetivamente ajustada do provável. Nas palavras do autor: 
Tudo se passa como se o futuro objetivo, que está em potência no presente, não pudesse advir senão com a colaboração ou até cumplicidade de uma prática que por sua vez é comandada por esse futuro objetivo. (BOURDIEU, 2013, p. 124).

Assim a predisposição dos alunos em suas escolhas são é condicionada por suas chances de sucesso em seus investimentos escolares. E sendo essa predisposição fruto do habitus essa escolha do provável tende a ser mais um mecanismo de reprodução. No caso do sistema escolar brasileiro, de reprodução das desigualdades de distribuição de capital cultural.

Ressaltamos ainda a retirada de espaço de componentes curriculares como a filosofia e a sociologia, as artes e a educação física, que ferem a dimensão da formação crítica/ humana/cidadã do sujeito.

Apenas português e matemática são, de acordo com a reforma, as únicas disciplinas a serem lecionadas obrigatoriamente ao longo de todos os anos do ensino médio, também será legitimada a prática já comum de professores lecionarem disciplinas diferentes das de sua área de formação. A obrigatoriedade de se lecionar conteúdos de sociologia presentes na BNCC não obriga nem a oferta pelos estabelecimentos de ensino de uma disciplina específica, nem a contratação de licenciados da área para lecionar esses conteúdos, que poderão ser ministrados por um profissional com formação em outra disciplina, como história, por exemplo.

Legitima-se, desse modo, o despreparo e a baixa qualidade para o ensino de certos conteúdos, além da já habitual dispensa de contratação de professores com formação específica para lecionar conteúdos de sua área de formação, o que colabora para a precarização da oferta de uma educação integral e de qualidade para formar indivíduos não apenas para o mercado de trabalho, mas também para exercer sua cidadania de modo crítico e autônomo. 0 direito dos estudantes de acesso ao conhecimento para uma formação geral, integral, científica e de qualidade parece estar negado.

Um outro ponto controverso da reforma, e que corrobora as argumentações apresentadas nesta seção, diz respeito à possibilidade da contratação de profissionais com notório saber para lecionar na educação técnica e profissional, tornando desnecessária a formação pedagógica para se lecionar nessas modalidades de ensino. 0 que, por sua vez, pode abrir precedentes para a contratação de profissionais não licenciados para atuarem em outras modalidades de ensino pelo critério de notório saber.

Os idealizadores da reforma parecem ignorar que algumas das maiores dificuldades enfrentadas pelo ensino público no país se relacionam às precárias condições de infraestrutura e funcionamento de grande parte das escolas, além das más condições de trabalho, desvalorização da carreira e da baixa qualidade da formação docente. Será possível aumentar a carga horária em direção ao ensino integral e oferecer todos os itinerários formativos com qualidade quando uma grande parte das escolas públicas enfrenta problemas de infraestrutura e falta de professores em diversas disciplinas? Como conciliar o ensino integral à realidade de um grande número de alunos que precisam trabalhar? Qual a real possibilidade de se investir em infraestrutura tanto para viabilizar o ensino integral como para o funcionamento de escolas de formação técnica e profissional (que exigem altos investimentos) em um contexto de políticas de austeridade que congelaram os gastos públicos por 20 anos? Essas são questões importantes que a reforma parece ignorar. 
Mesmo com tantas perguntas em aberto, o Ministério da Educação (MEC) tem divulgado propagandas acerca da Reforma do Ensino Médio, apontando sua "contribuição" para a autonomia do aluno e estímulo à sua capacidade de escolha. Percebe-se uma intensa preocupação em convencer a população da importância da Reforma, embora para além do convencimento, haja o caráter coercitivo internalizado na lei, tanto pela sua imposição sem debate com as bases, tanto pela repressão que o Estado tem investido contra os movimentos que de fato organizam oposições a ela, como as ocupações estudantis em Universidades e Institutos Federais, por exemplo. Há uma forte relação desta reflexão com a compreensão de Gramsci sobre o Estado Ampliado e as respectivas articulações das relações de poder.

Para Gramsci, o Estado moderno é justamente a existência da dualidade da dimensão de força e consenso. A "sociedade política" (governo de forma restrita) é onde se exerce o poder via dominação, no peso da coerção, leis, aparato repressivo de violência legítima; enquanto o que o autor denominou de "sociedade civil" são os espaços onde ocorre o exercício de poder via direção política e consenso. No conjunto de relações sociais da "sociedade civil" está inserido o fluxo constante da vida cotidiana em sociedade. Mediante a materialidade destas relações, as instituições e as ideologias as organizam de forma heterogênea, mas como representação de demandas e projetos em disputa na construção de hegemonia mediante estas mesmas instituições. As duas instâncias, "sociedade política" e "sociedade civil" fazem parte do Estado, em sentido integral, e são separadas com fins puramente metodológicos para compreendermos que muitas vezes o poder que parece estar ultrapassando "fronteiras" entre o público e o privado, é na realidade a forma como ocorre a hegemonia, atravessando necessariamente aquelas instâncias.

A tentativa deconstrução deumpensamentohegemônicorelacionadoà propagandeada necessidade de uma reforma, passa então tanto pela força de consenso, onde os meios de comunicação são fundamentais, como também pelo aspecto coercitivo, repressivo e autoritário. Ambos caminham juntos neste processo, em fins de viabilizar a aceitação de um projeto que beneficia um grupo, mas que sempre será divulgado como um benefício comum e de amplo interesse.

Porém, essa lógica de formação de consenso não se inicia com a reforma, embora possamos perceber seu aprofundamento principalmente após as reações estudantis, altamente reprimidas pelo aparato coercitivo. As próprias divulgações constantes prévias da ineficácia do Ensino Médio já apontam para tal fim e é importante refletirmos sobre de que maneira a própria Reforma e seu latente fracasso não serão assim instrumentos de formação de consenso para legitimação de lógicas ainda mais fortes de privatização na Educação. O envolvimento profundo de instituições como a FIESP e a FIRJAN nas discussões sobre a Reforma do Ensino Médio também não serão simples coincidências, assim como a divulgação, ainda anterior à concretização da Reforma, na "nova formação de docentes", na Faculdade Sesi de Educação (SP), "cujas primeiras turmas de graduação começaram a estudar em fevereiro de 2017. São oferecidas as formações em Linguagens, Ciências da Natureza, Ciências Humanas e Matemática". Segundo próprio site da FIESP, o objetivo é formar profissionais para os desafios do século XXI, com um discurso de melhoria nas condições gerais - para professores e alunos.

Aqui vemos claramente o EM como instrumento de luta política como bem designa Bourdieu (2013). Os mestres da economia, aqui encarnados como o atual empresariado brasileiro, muito representado nesse sentido pelo sistema S de ensino, são um instrumento de pressão permanente sobre o sistema educacional público. Segundo Bourdieu (2013): 
Os mestres da economia tem interesse em suprimir o diploma e seu fundamento, ou seja, a autonomia do sistema educacional; interessaIhes a confusão completa entre o diploma e o cargo. (BOURDIEU, 2013, p. 152)

Bourdieu aponta para a influência empresarial na educação orientando as demandas de acordo com seus interesses específicos, para garantia de mão de obra e criando assim um sistema de ensino tripartido, onde cada grupo social terá acesso à uma educação com objetivos específicos:

A contradição patronal-conservar as vantagens que a titulação oferece à reprodução da classe dominante sem deixar de controlar o acesso das outras classes aos poderes conferidos pelo diploma - encontra sua solução no desenvolvimento de instituições de ensino privado, das empresas de formação, recuperação e reciclagem incrementadas pela aparição da "formação permanente" e talvez, mais geralmente, na instauração de um sistema de ensino tripartido: grandes écoles para reprodução da classe dominante; escolas técnicas, controladas pela economia, para reprodução da força qualificada de trabalho; universidade para a reprodução da universidade.

Para o autor, os compradores de força de trabalho tendem a querer, cada vez mais, diminuir as possibilidades de autonomia dos sistemas de ensino, para que assim possam inserir suas demandas de forma mais direta na educação. No contexto atual brasileiro, percebemos a interferência de tais corporações não apenas no que se refere à chamada Reforma do Ensino Médio, mas em todo um pacote de reformas que pretendem aprofundar as desigualdades no país desde a idade escolar até o fim da trajetória de trabalho dos indivíduos, alterando inclusive direitos trabalhistas e o sistema de aposentadorias. De fato, um projeto de nação vem sendo construído pelo Estado, representante dos interesses de grupos específicos e que se beneficiam diretamente da(s) Reforma(s), embora o discurso para formação hegemônica continua a ser o do então ministro da Educação, Mendonça Filho, que disse recentemente "que aceita democraticamente as críticas, mas que vai levar adiante a reforma do ensino médio", porque "interessa aos jovens do Brasil". A declaração foi feita em audiência pública da comissão mista do Congresso Nacional que analisou a medida provisória MP 746/2016 que viria a se transformar no texto da lei 13.415 de 16 de fevereiro de 2017.

\section{CONCLUSÃO}

Como apontado anteriormente, o Ensino Médio historicamente constituiu-se com uma função propedêutica e mais recentemente, de terminalidade do Ensino Básico. 0 fato de que nenhuma de tais funções é atendida plenamente no Ensino Público, especialmente municipais e estaduais, o que acabou gerando um discurso de necessidade de mudança - e utilizado fortemente como legitimação na tentativa de consenso da Reforma atual. De fato, o Ensino Médio da Rede pública não insere os jovens de classes mais baixas no Ensino Superior em larga escala. Embora alguns programas sociais nos últimos anos tenham alargado um pouco tal realidade, a proporção de estudantes pertencentes ao quinto mais pobre da população, com renda per capita média de R\$ 192, era 1,2\% em 2004 e chegou a apenas 7,6\% dos alunos de faculdades públicas em 2014, em pesquisa do IBGE. 
Isto relaciona-se diretamente com o que Bourdieu nos apresenta ao indicar que a escola tem toda sua estrutura baseada no habitus da classe dominante e por isso, as classes que não possuem tal inserção possuem tanta dificuldade de adequação ao ambiente escolar e consequentemente ao ensino superior. "Ora, vê-se nas oportunidades de acesso ao ensino superior o resultado de uma seleção direta ou indireta que, ao longo da escolaridade, pesa com rigor desigual sobre os sujeitos das diferentes classes sociais" (BOURDIEU, 2013, p. 41). 0 conceito de habitus fornece o entendimento de como os indivíduos, que ao nascerem encontram uma complexa rede de funções estruturadas e bem definidas, internalizam as maneiras de ser comuns ao seu grupo.

Como formação cidadã, o Ensino Médio também não vem apresentando bons resultados, basta observarmos os níveis de analfabetismo funcional.

Porém, também é fato, que algumas tentativas foram realizadas nos últimos anos, como as instalações de Institutos Federais pelo país. O conceito de um Ensino Médio integrado, que pretende capacitar profissionalmente sem ser tecnicista, poderia ser uma saída à tal crise, mas ao invés de investimentos em tal possibilidade, temos um retrocesso à modelos que já deveriam ter sidos superados enquanto possíveis soluções.

Há muitas aproximações entre as últimas experiências educacionais nos Institutos Federais e o pensamento de Gramsci, que poderiam ser aprofundadas. Para o autor, a Escola deveria ser unitária, difundindo uma cultura geral técnica que lhe dê condições "[...] senão de 'criar' autonomamente a solução correta, pelo menos de saber julgar entre as soluções projetadas pelos especialistas aquelas mais justas do ponto de vista 'sintético' da técnica política”. (GRAMSCI, 1977, p. 1534). Uma escola que esteja voltada para a organização da cultura e que permita a construção da hegemonia por parte dos grupos subalternos, onde os alunos conquistem habilidades diretivas e instrumentais. Porém, tais possibilidades vão na contramão de um ensino que nos é imposto neste momento, que mantêm um tipo de escola para cada grupo social, reproduzindo desigualdades.

Acreditamos que os interesses desta reforma estão muito mais vinculados a uma lógica empresarial do que de fato uma resolução que atenda os interesses gerais; mesmo que para a formação de consenso, propagandeou-se o atendimento a demandas coletivas. Enfim, a reforma pretende de fato solucionar a ineficácia do Ensino Médio ou aprofundar ainda mais seus problemas, já que suas propostas tendem a privilegiar um ensino técnico restritivo para as classes mais pobres, enquanto a classe dirigente continua a ter formação dirigente, propedêutica e humanista?

\section{REFERÊNCIAS}

1. ALVES, Sandra Cristina Santos. A educação profissionalizante durante o estado ditatorial. Anais do $\mathrm{V}$ Congresso norte-nordeste de pesquisa e inovação. Instituto Federal de Alagoas, 2010.

2. BOURDIEU P. Escritos de Educação. Editora Vozes, Petrópolis, 2013.

3. BRASIL. Lei no 9.394, de 20 de dezembro de 1996: Estabelece as diretrizes e bases da educação nacional. Congresso Nacional. Disponível em: http://www.planalto.gov.br/ ccivil_03/leis/L9394.htm.

4. $\quad$ BRASIL. Decreto 2208 de 17 de abril de 1997: Regulamenta o $\S 2^{\circ}$ do art. 36 e os arts. 39 a 42 da Lei no 9.394, de 20 de dezembro de 1996, que estabelece as diretrizes e bases da educação nacional. Disponível em http://www.planalto.gov.br/ccivil_03/decreto/d2208.htm. 
5. BRASIL. MINISTÉRIO DA EDUCAÇÃO. Educação Profissional Técnica de Nível Médio Integrada ao Ensino Médio. Documento Base. Brasília, 2007. Disponível em: http:// portal.mec.gov.br/setec/arquivos/pdf/documento_base.pdf.

6. BRASIL. Lei $n^{\circ} 13.415$ de 16 de fevereiro de 2017. Altera as Leis nos 9.394, de 20 de dezembro de 1996, que estabelece as diretrizes e bases da educação nacional. Disponível em : http://www.planalto.gov.br/ccivil_03/_ato2015-2018/2017/lei/L13415.htm

7. CIAVATTA, Maria. O Ensino Integrado, a Politecnia e a Educação Omnilateral. Por Que Lutamos? Revista Trabalho \& Educação. v.23 n.1. p.187-205. 2014

8. CHERVEL A. História das disciplinas escolares: reflexões sobre um campo de pesquisa. Teoria e Educação, n²2, p. 177-277, Goiânia, 1992.

9. FREIRE, Paulo. Educação e Atualidade Brasileira, São Paulo: Cortez Editora, 2012.

10. FRIGOTTO G. Uma década do decreto no 5.154/2004 e do proeja: balanço e perspectivas. HOLOS, Ano 32, Vol. 6.

11. GHIRALDELLI JR., Paulo. História da educação. São Paulo: Cortez, 1990

12. GOODSON, I. F. Currículo: Teoria e História. Editora Vozes, Petrópolis, 2010.

13. GRAMSCI, Antonio. Quaderni del Carcere. Edição crítica do Instituto Gramsci, org. Valentino Gerratana, 1977, ed. Einaudi, Torino.

14. LOPES, A. C; MACEDO, E. Teorias de Currículo. Editora Cortez, São Paulo, 2011.

15. RAMOS, M.N. O Ensino Médio ao longo do século XX: Um projeto inacabado. In: STEPHANOU, M.; BASTOS, M.H.C. (Org.) História e Memórias da Educação no Brasil. Editora Vozes, Petrópolis, 2005.

16. XAVIER, Maria Elizabeth Sampaio Prado. História da Educação: a escola no Brasil. São Paulo: FTD, 1994. 